\title{
Numerical simulation and combustion analysis of coal and biomass co-combustion
}

\author{
Jiahu $\mathrm{Li}^{*}$, Zhi Wang, and Chi Ma \\ Department of Power Engineering, North China Electric Power University, Baoding, China
}

\begin{abstract}
China began entering the 14th Five-Year Plan period in 2021. With the proposed carbon-neutral long-term goal, the strategic position of clean energy is becoming increasingly prominent. using biomass power generation is one of the main application ways. In order to study the mixed combustion process of coal and biomass, this paper takes 300MW lignite boiler as the research object and uses Fluent software to explore the influence of biomass types and the location of biomass nozzle on the mixed combustion, and obtains the corresponding temperature field, flue gas component field and the distribution of pollutant NO. The results showed that when the biomass particles were sprayed into a fixed position with a certain proportion, the NO emission of wheat, corn and cotton straw was reduced, and the effect of wheat straw was the most obvious. When a certain proportion of wheat straw and coal are co-fired, the higher the biomass nozzle position, the higher the peak temperature in the main combustion zone, and the better the emission reduction effect of NO.
\end{abstract}

Keywords: Biomass energy, Combustion characteristic, Mixed burning, Numerical simulation.

\section{Introduction}

In recent years, China has vigorously developed renewable and clean energy, and the proportion of consumption has been increasing. The national 3060 target has been included in the 14th Five-Year Plan, requiring to peak $\mathrm{CO}_{2}$ emissions by 2030. As one of the renewable energy sources, biomass is often used in coupling with coal in large thermal power generating units [1]. This way not only saves coal resources, but also greatly reduces the emission of pollutants, which meets the development requirements of the country [2].

In the mixed combustion characteristics of biomass and pulverized coal, Alexander Stroh [3] studied the changes in the fuel properties after adding biomass to powdered coal, arguing that biomass is a good substitute for powdered coal fuel while keeping the combustion system constant. Aneta Magdziarz [5] studied the forestry biomass and sludge through thermal weight experiment, compared the results with the corresponding mixture combustion results, and found that both the biomass and sludge can improve the combustion characteristics of the test coal powder and improve the combustion efficiency.

\footnotetext{
*Corresponding author email: 1ijiahu01@163.com
} 
Lu GuangWu [6] through the comparison of the thermogravimetric experiments of biomass, pulverized coal and their mixtures, there are founds that the ignition temperature, maximum combustion rate and burnout temperature decrease obviously with the increase of the mixing combustion ratio, and the combustion characteristics of coal are improved obviously.

Effects of biomass mixed combustion on the environment, Tian Hong et al. [7] through the analysis of the combustion characteristics and dynamics of the mixed combustion of materials and coal, it is found that the addition of biomass can promote the combustion of pulverized coal, improve the combustion efficiency and reduce the pollution to the environment. Zhang Jin [8] and Li Jiahu [9] found that the addition of biomass had an obvious inhibiting effect on the production of pollutants, and the carbon content of fly ash would gradually decrease. Wang Kai [10] By comparing the injection positions of the first layer and the second layer of biomass gas, it is found that the combustion difference mainly exists in these two positions under the two working conditions. The injection of the first layer is conducive to the formation of reducing atmosphere earlier, so $\mathrm{NO}_{\mathrm{X}}$ Lower emissions. Zakieh Khorshidi et al. [11] applied the new $\mathrm{CO}_{2}$ capture technology to an Australian coal-fired power plant in order to study the impact of biomass mixing on raw coal. He found that biomass was mixed by $10 \%$ under the original working conditions, and $\mathrm{CO}_{2}$ emissions were reduced by $9 \%$ based on the original basis. Yonmo Sung et al. [12] studied the synergistic effect of woody biomass and coal combustion in air, improved the combustion rate of carbon, and biomass can better control $\mathrm{NO}_{\mathrm{x}}$ on coal with low nitrogen content.

Taking corners of $300 \mathrm{MW}$ tangential lignite unit as the research object, using Gambit software 1:1 simulation modeling, meshing, Fluent software is adopted to improve the working condition of pure coal and pulverized coal and biomass particles numerical simulation of combustion condition, and then to get the results of numerical simulation were analyzed, and for burning coal and biomass mixing engineering experiment research to provide the corresponding theoretical reference.

\section{Methods}

\subsection{Physical model}
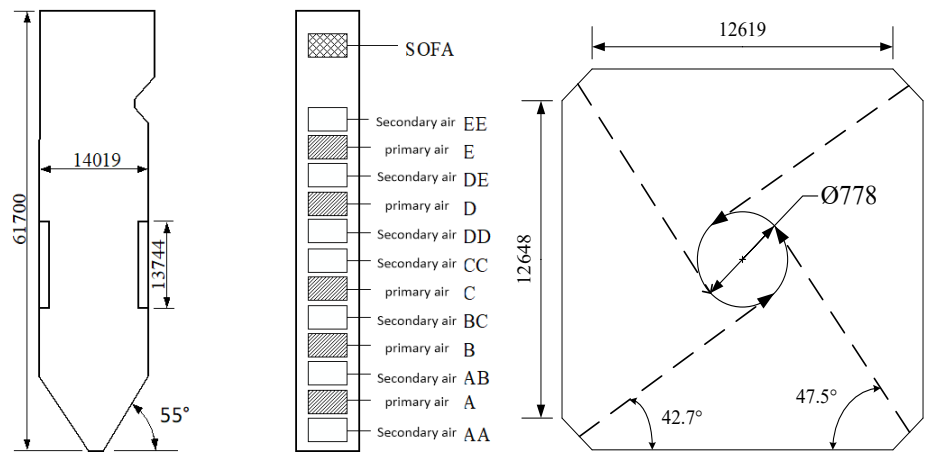

Fig. 1. Furnace model and burner arrangement.

The research object of this paper is a $300 \mathrm{MW}$ quadrilateral circular lignite boiler. Burner A total of five layers, burner top-down Numbers for A, B, C, D, E, secondary air from the bottom up Numbers for AA, AB, BC, CC, DD, DE, EE, burner can bobbing up 
and down, maximum swing Angle for plus or minus $30^{\circ}$. Schematic diagram of boiler and burner arrangement are shown in Fig. 1. The diameter of tangential circle is $778 \mathrm{~mm}$.

\subsection{Fuel information}

The main parameters of coal types and biomass particles involved in the simulated conditions in this paper are shown in Table 1.

Table 1. Elemental analysis and industrial analysis of fuels.

\begin{tabular}{|c|c|c|c|c|c|c|c|c|c|c|}
\hline \multirow{2}{*}{$\begin{array}{l}\text { The name of } \\
\text { the fuel }\end{array}$} & \multicolumn{5}{|c|}{ Elemental analysis $/ \%$} & \multicolumn{4}{|c|}{ Industrial analysis $/ \%$} & \multirow{2}{*}{$\begin{array}{c}\text { Low } \\
\text { calorific } \\
\text { value } \\
/ \mathrm{MJ}^{2} \mathrm{~kg}^{-1}\end{array}$} \\
\hline & $\mathrm{C}_{\mathrm{ar}}$ & $\mathrm{H}_{\mathrm{ar}}$ & $\mathrm{O}_{\mathrm{ar}}$ & $\mathrm{N}_{\mathrm{ar}}$ & $\mathrm{S}_{\mathrm{ar}}$ & $\mathrm{M}_{\mathrm{ar}}$ & $\mathrm{A}_{\mathrm{ar}}$ & $\mathrm{FC}_{\mathrm{ar}}$ & $\mathrm{V}_{\mathrm{ar}}$ & \\
\hline Coal & 40.25 & 3.28 & 9.74 & 0.71 & 0.43 & 29.6 & 15.99 & 28.31 & 26.1 & 14.51 \\
\hline Cotton stalks & 39.41 & 4.68 & 33.9 & 0.84 & 0.13 & 10.5 & 10.54 & 16.79 & 62.17 & 14.4 \\
\hline Corn stover & 37.35 & 4.43 & 33.62 & 0.96 & 0.08 & 5.95 & 17.61 & 13.82 & 62.62 & 16.7 \\
\hline $\begin{array}{l}\text { The wheat } \\
\text { straw }\end{array}$ & 43.71 & 4.76 & 36.36 & 0.54 & 0.18 & 9.83 & 4.62 & 14.39 & 71.16 & 15.54 \\
\hline
\end{tabular}

\subsection{Working condition of research}

Based on the $100 \%$ BECR working condition, the blending ratio of biomass particles was set as $15 \%$, and the injection position was the burner nozzle of the lowest layer (A layer). The excess air coefficient of pulverized coal and biomass particles were both 1.2. Three kinds of biomass common in northern China were selected for blending, to determine the best blending material. Then take this material as the mixing type, keep other conditions unchanged, in different positions namely from the burner A, B, C, D, E layer spray into the mixed combustion with pulverized coal, To study the effect of the material nozzle position on the mixing characteristics. and the thermodynamic calculation results were shown in Table 2 .

Table 2. Thermodynamic calculation results.

\begin{tabular}{lcccc}
\hline project & Pure coal & Cotton stalks & Corn stover & The wheat straw \\
\hline Coal burning $(\mathrm{kg} / \mathrm{s})$ & 51.54 & 43.81 & 43.81 & 43.81 \\
Mixed burning ratio (\%) & 0 & 15 & 15 & 15 \\
Biological mass $(\mathrm{kg} / \mathrm{s})$ & 0 & 7.79 & 6.72 & 7.22 \\
Total air volume $\left(\mathrm{m}^{3} / \mathrm{s}\right)$ & 255.9 & 251.35 & 244.74 & 251.67 \\
Primary wind rate (\%) & 25 & 25 & 25 & 25 \\
Secondary air rate (\%) & 55 & 55 & 55 & 55 \\
Burnout air rate $(\%)$ & 20 & 20 & 20 & 20 \\
Primary wind speed $(\mathrm{m} / \mathrm{s})$ & 28.95 & 28.43 & 27.68 & 28.47 \\
Secondary wind speed $(\mathrm{m} / \mathrm{s})$ & 44.45 & 43.66 & 42.52 & 43.72 \\
Burnout wind speed $(\mathrm{m} / \mathrm{s})$ & 48.09 & 47.24 & 45.99 & 47.3 \\
\hline
\end{tabular}

\section{Results analysis of co-firing different biomass}

This chapter through the simulation of pure coal combustion conditions and from the A layer burner were injected into cotton straw, corn straw, wheat straw three mixed combustion conditions, analysis of the optimal biomass burning species. 


\subsection{Velocity field}

The section of the primary air nozzle in the bottom layer ( A layer ) of the four working conditions is intercepted to compare and analyze the influence of the mixed combustion on the flow field. The velocity vector diagram is shown in Figure 2. It can be seen from the figure that the three kinds of biomass are burned in the furnace from the primary air nozzle and all can form good velocity tangential circle. In the case of mixing combustion, the distribution of velocity field in the furnace is reasonable to meet the demand of air distribution in pulverized coal combustion. In the case of three kinds of biomass mixed firing, the difference of primary wind speed is very small, and the shape and size of tangential circle formed are basically the same.
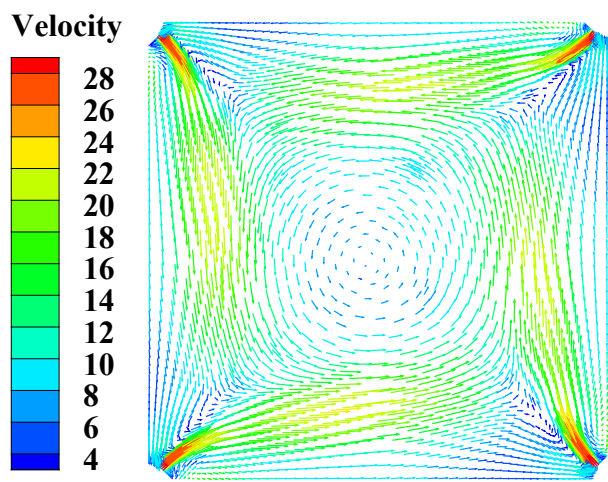

A) Pure coal

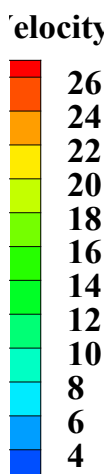

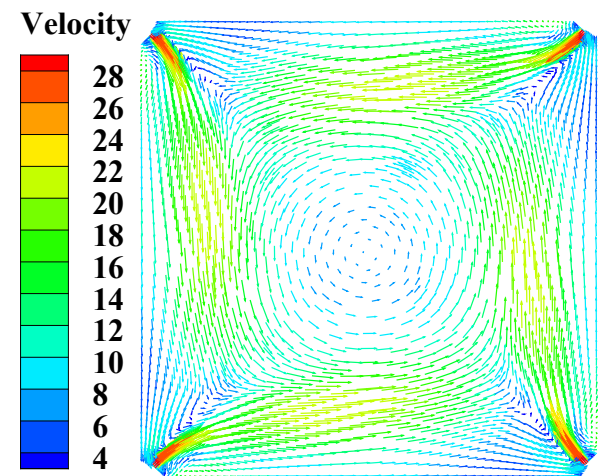

B) Cotton straw

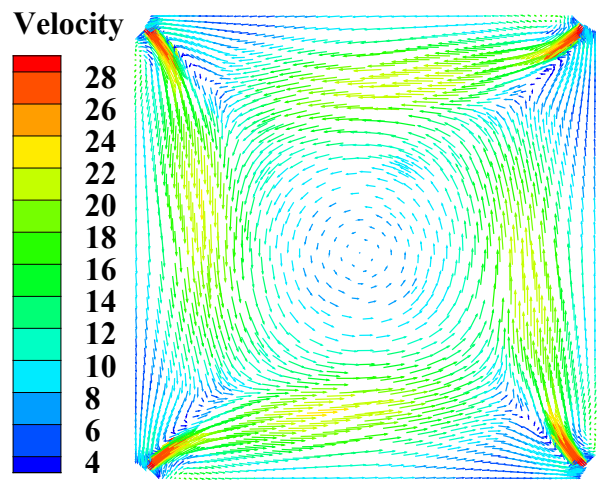

C) Corn stalks

D) Wheat straw

Fig. 2. Velocity field of the lowest primary air nozzle section. 


\subsection{Distribution of temperature field}
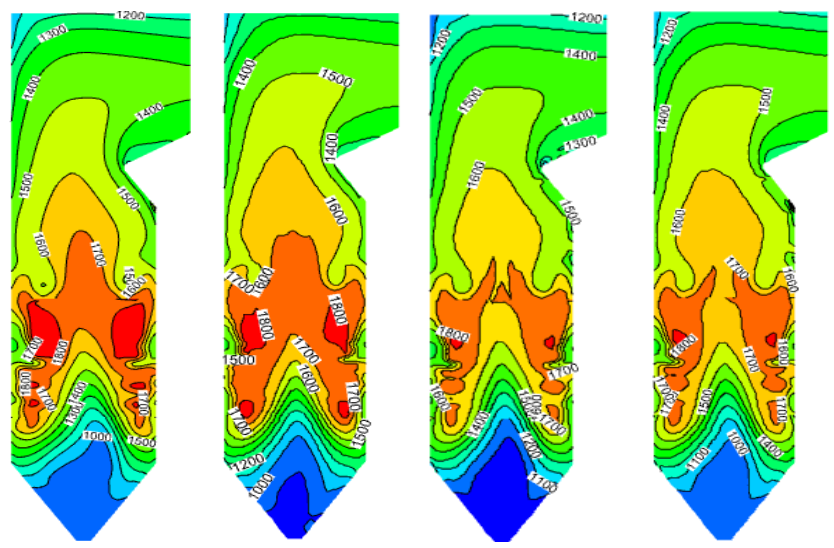

a) pure coal b) Cotton straw c) Corn stalks d) Wheat straw

Fig. 3. Temperature distribution of longitudinal sections in different biomass furnaces.

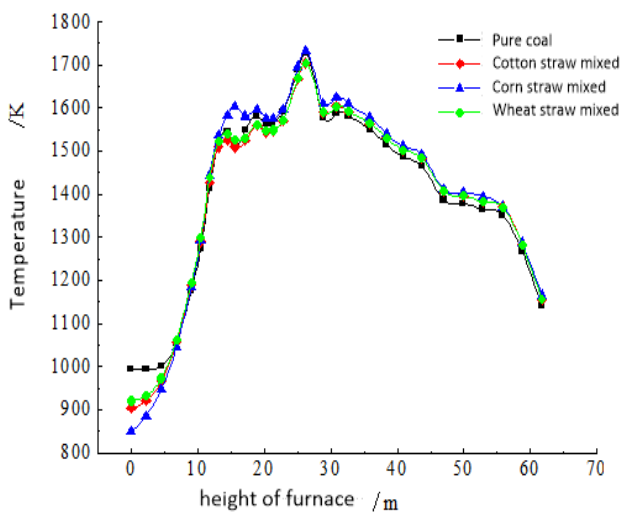

Fig. 4. Temperature of furnace section varies with the height of furnace.

Fig. 3 is the longitudinal sectional temperature distribution diagram of the furnace under three different biomass and pure coal conditions. In order to better observe the change rule of the temperature field in the direction of the furnace height under three mixed firing conditions, characteristic sections such as the burner nozzle are intercepted to form the curve diagram as shown in Fig. 4. As can be seen from Fig. 3, the temperature in the cold ash hopper area is the lowest, and the high temperature area is mainly distributed in the main combustion area, which is symmetrically distributed, and the combustion is in good condition. Due to the differences in calorific values and volatiles of the three biomass, the temperature of the main combustion zone presented different rules after the blending burning. When the blending burning of cotton and wheat straw was done, the temperature of the main combustion zone decreased to a certain extent, but the range of high temperature in the main combustion zone after the blending burning of corn and wheat straw was significantly expanded. The volatiles of the three kinds of biomass are higher than that of pulverized coal, and the heat released after mixing and burning promotes the combustion of the surrounding pulverized coal and improves the combustion characteristics. The outlet smoke temperature of the three mixed combustion conditions of mixed cotton, corn and wheat straw are $1341 \mathrm{~K}, 1349 \mathrm{~K}$ and $1344 \mathrm{~K}$, respectively increased by $18 \mathrm{~K}, 26 \mathrm{~K}$ 
and $21 \mathrm{~K}$, compared with pure coal conditions, which shows that mixed biomass improves the outlet temperature of the furnace.

It can be found from the Fig. 4 that the average temperature of the section varies with the height of the furnace under four working conditions, which increases first and then decreases. The temperature of the cold ash hopper decreases after biomass sintering, which reduces the possibility of slagging at the bottom, and the temperature of corn stalk decreases most obviously. It is further known that the temperature of the main burning zone increases to a certain extent when the corn straw is mixed, and the peak temperature is $1733.4 \mathrm{~K}$. When cotton and wheat straw were mixed, the temperature decreased, but the decrease was small and negligible. As the reaction goes on, the overall temperature of the three mixed burning conditions is higher than that of the pure coal burning condition after the air is burned out, but the range is not large, and the influence on the temperature field in the furnace is small, and finally decreases to a certain level.

\subsection{Distribution of flue gas components}

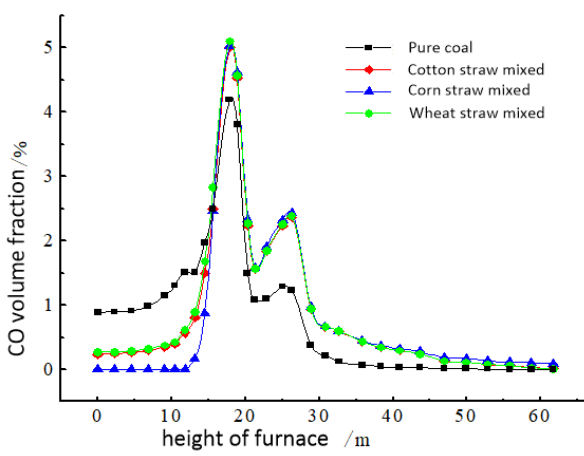

(a)

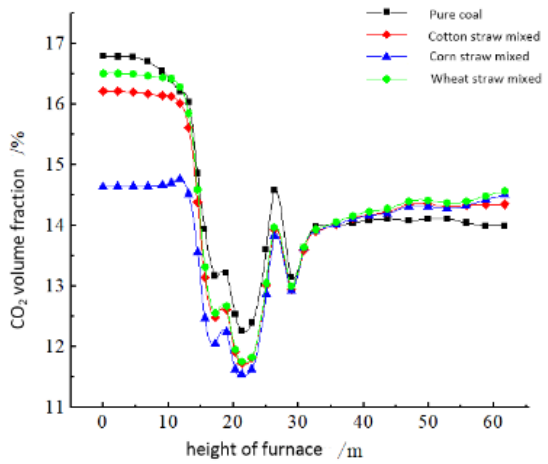

(b)

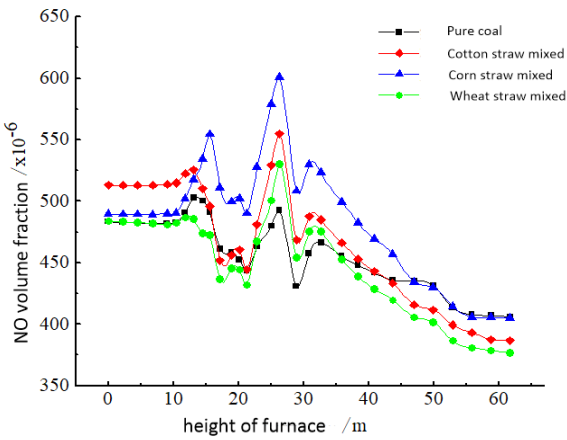

(c)

Fig. 5. Variation of flue gas components along furnace height.

Fig. 5 shows under different biomass mixing and firing respectively $\mathrm{CO}, \mathrm{CO}_{2}$, and $\mathrm{NO}$ the average volume fraction of the section changes along the height of the furnace. The primary air nozzle section in the main combustion area is taken as the characteristic section. it can be seen from Fig. 5a) that the distribution of $\mathrm{CO}$ volume fraction along the furnace height is the same in three working conditions and pure coal burning conditions. In the cold ash hopper area, the $\mathrm{CO}$ volume fraction of pure coal is higher than that of the three sintering conditions, and the $\mathrm{CO}$ volume fraction of corn stalk is the lowest under the sintering condition, and the $\mathrm{CO}$ volume fraction is zero. The peak value of $\mathrm{CO}$ in the main 
combustion zone appears in the B layer of the burner, which is higher than that of pure pulverized coal combustion in the mixing combustion condition, and the peak value is the same in the three mixing combustion conditions. The trough value appears at the D layer of the burner nozzle. Then, with the increase of the height of the furnace, the $\mathrm{CO}$ volume fraction increases to the exhaust air layer, and the pulverized coal burns further. The CO volume fraction in the four groups of working conditions gradually decreases to close to 0 .

$\mathrm{CO}_{2}$ as shown in Fig. 5b), the four groups of working conditions have the same distribution law along the direction of furnace height, that is, the highest content at the bottom of the furnace, with the rise of the furnace, the combustion reaction in the main combustion zone fluctuates violently, and further combustion heat release in the burnout zone, rises to a certain value, and gradually stabilizes. $\mathrm{CO}_{2}$ It is mainly concentrated in the cold ash hopper area, and the mixing burning condition is lower than the pure coal burning condition, in which the mixing burning of corn straw $\mathrm{CO}_{2}$ the lowest content. The excess air coefficient in the main combustion zone is less than 1 , in a reductive atmosphere, $\mathrm{CO}_{2}$ the volume fraction in this region is low and has the lowest point. Among them, the variation of cotton and wheat blending burning condition is almost the same, while the blending burning condition of corn straw is $\mathrm{CO}_{2}$ the content is slightly lower than the other two conditions. The $\mathrm{CO}_{2}$ in the burnout area under three mixing burning conditions And when the burning substance is wheat straw, $\mathrm{CO}_{2}$ the highest content.

The variation of $\mathrm{NO}$ volume fraction along the furnace height is shown in Fig. 6. It can be seen from the figure that the distribution law of NO volume fraction along the direction of furnace height in mixing combustion condition and pure coal burning condition is basically the same. It is maintained at a higher level at the bottom of the furnace, and decreases to a certain extent in the main combustion zone, and reaches the maximum value in the transition zone between the main combustion zone and the burnout air layer. In the burnout air nozzle, the volume fraction of NO decreases, and finally drops to the top of the furnace Down to a certain number. In the cold ash hopper area, the volume fraction of NO in the mixed burning of wheat straw and pure coal is the same, and the other two mixed burning conditions are all higher than that in the pure burning conditions, which is related to the nitrogen content of biomass and its volatiles. The excess air coefficient in the main combustion zone is less than 1 , and the reducing atmosphere is strong, which will inhibit the fuel type $\mathrm{NO}_{\mathrm{x}}$. However, in the three working conditions, $\mathrm{NO}$ content in this area is higher than that in the pure coal burning condition, which is due to the different calorific values of biomass and lignite. The highest peak value of NO volume fraction is in the working condition of mixing corn straw. Finally, at the horizontal flue and furnace exit, the volume fraction of NO decreased not significantly with the addition of corn straw, but significantly with the addition of cotton straw and wheat straw, and the decrease range of the addition of wheat straw was the largest. The NO volume fraction of pure coal and blended burning cotton, corn and wheat straw at the exit of furnace is respectively $420.8 \times 10-6,392 \times 10-6,416.8 \times 10-6$ and $382.8 \times 10-6$.

From the above analysis, the distribution law of $\mathrm{CO}, \mathrm{CO} 2$ and $\mathrm{NO}$ content along the furnace height direction is consistent with mixed biomass and pure coal burning conditions. For the three biomass, the lowest $\mathrm{CO}$ volume score and the highest $\mathrm{CO} 2$ content were wheat straw. when the proportion of biomass mixing sintering is $15 \%$, the three kinds of biomass mixing sintering can reduce NO emission, and the mixing sintering of wheat straw has the most obvious effect. 


\section{Results analysis of different biomass nozzle positions}

This chapter analyzes the influence of biomass nozzle position on co-combustion characteristics by simulating the co-combustion of pulverized coal and wheat straw injected from burner A, B, C, D and E layers.

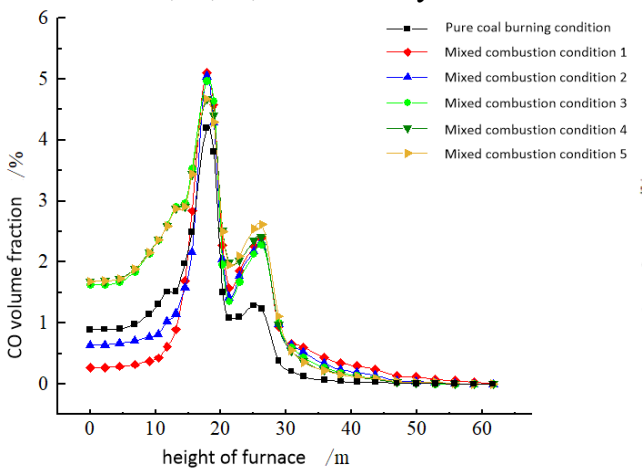

(a)

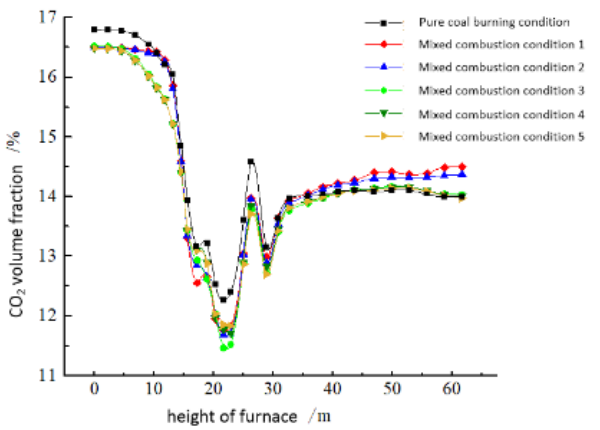

b)

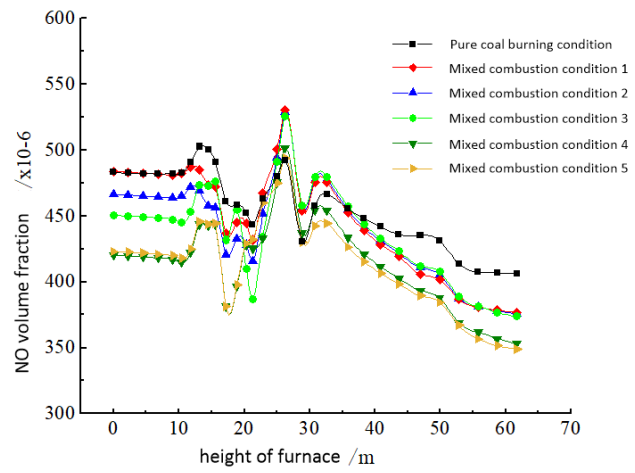

c)

Fig. 6. Composition distribution of flue gas.

In this section, the main materials are mixed and burned in different positions $\mathrm{CO}, \mathrm{CO}_{2}$ and NO the influence of distribution. Fig. 6 shows the distribution of corresponding components along the furnace height. Fig. 6a) shows the distribution of $\mathrm{CO}$ volume fraction along the direction of furnace height. It can be seen from the figure that the distribution rule of the five mixed combustion conditions is consistent with that of the pure coal burning condition, that is, the $\mathrm{CO}$ volume fraction is low in the ash bucket area, the highest in the main combustion area, and the peak value is reached in this area. As the reaction goes on, the $\mathrm{CO}$ volume fraction is almost 0 at the top of the furnace. In the cold ash area, the $\mathrm{CO}$ volume fraction of mixed combustion conditions 1 and 2 is lower than that of pure coal burning, while the situation of mixed combustion conditions 3,4 and 5 is opposite. The excess air coefficient in the main combustion zone is less than 1 , and the reducing atmosphere is strong. The volume fraction of $\mathrm{CO}$ in this area is high, and the peak value is reached at the nozzle of the burner in Layer B, which has no relation with the location of the biomass nozzle. In the exhaust air zone, the volume fraction of CO increases slightly in the exhaust air layer, and then the further reaction decreases to a certain value.

Observed Figure 6b), it can be seen that $\mathrm{CO}_{2}$ the volume fraction at the bottom of the furnace is at a higher level, and with the increase of the furnace height, $\mathrm{CO}_{2}$ the volume fraction gradually decreases, fluctuates up and down in the main combustion zone, and appears a minimum value. After further oxidation and combustion, the $\mathrm{CO}_{2}$ volume fraction 
increases with the furnace height and finally stabilizes to a certain level. Further analysis found that in the cold ash hopper area, $\mathrm{CO}_{2}$ under five mixed combustion conditions The volume fraction is lower than that in pure coal condition, and the $\mathrm{CO}_{2}$ in mixed combustion condition 1 and 2 the volume fraction is very similar, and the volume fraction of the other three mixed combustion conditions is very similar. And it is not difficult to find the $\mathrm{CO}_{2}$ in the mixed combustion condition of the main combustion zone the volume fraction is lower than that in pure coal burning condition, it can be seen that the mixing of biomass enhances the reducing atmosphere in the main combustion zone. After burning out the wind layer, $\mathrm{CO}_{2}$ the volume fraction gradually increases to a certain value, and $\mathrm{CO}_{2}$ under mixed combustion condition The volume fraction is higher than that of pure coal burning condition.

The distribution of NO volume fraction along the furnace height is shown in Fig. 6c). It can be seen from the figure that the distribution of NO volume fraction along the direction of furnace height is the same as that of pure coal under the five mixed combustion conditions. At the bottom of the furnace, the volume fraction of NO in six conditions is at a high level. With the increase of the height of the furnace, the volume fraction of NO fluctuates up and down. Finally, the volume fraction of NO is further reduced to a certain level through the burnout air layer. In the cold ash hopper area, the volume fraction of NO is obviously lower than that in the pure coal burning condition except the mixed burning condition 1. In the main combustion zone, when the excess air coefficient is less than 1 , the volume fraction of NO appears the lowest value in the reductive environment. With the increase of the furnace height, the maximum value is achieved in the transition zone between the top secondary air and the burnout air layer. After the exhaust air layer, the volume fraction of NO further decreases and finally decreases to a certain value. Under the five kinds of mixed combustion conditions, the volume fraction of NO at the furnace outlet is lower than that in the pure coal burning condition, and the higher the biomass nozzle location is, the lower the volume fraction of NO.

According to the above analysis, the mixed combustion condition and the pure coal burning condition $\mathrm{CO}, \mathrm{CO}_{2}$, and $\mathrm{NO}$ the distribution law of volume fraction along the furnace height is basically the same. When biomass is mixed in different nozzle positions, the export $\mathrm{CO}_{2}$ the volume fraction is slightly higher than that of pure coal. when the position of biomass nozzle is arranged in the lower three layers, the reduction of NO volume fraction is roughly the same. Similarly, when the biomass nozzle position is arranged in the upper two layers, the damping effect is the same. In general, when the biomass nozzle is arranged in the top position, the NO volume fraction has the lowest emission.

\section{Conclusion}

(1) Compared with the pure coal burning condition, the temperature of the main burning zone will decrease slightly when the cotton and wheat straw are mixed burning, while the law of the corn straw is opposite. The furnace outlet temperature will be raised when the three kinds of biomass are mixed, but the range is not large, and the boiler operation will not be affected.

(2) Under the three kinds of biomass mixed combustion conditions, the distribution law of $\mathrm{CO}, \mathrm{CO}_{2}$ and $\mathrm{O}_{2}$ along the furnace height is consistent with the trend of pure coal. Under the three mixed combustion conditions, compared with pure coal, the $\mathrm{O}_{2}$ volume fraction at the outlet of the furnace is reduced, and the reduction value is the same. The export volume fraction of $\mathrm{CO}_{2}$ increased, and the largest increase was in wheat co-firing, with a better burnout. 
(3) Blending with cotton stalks, corn stalks, and wheat stalks can reduce NO emissions compared to pure coal burning conditions, and the reduction effect is best when blending with wheat.

(4) When the biomass vents are arranged in the primary air vents A, B, C, D, and E layers, the flow field at the center section of the vent where the biomass is located does not change significantly. The higher the position of the biomass nozzle, the higher the peak temperature of the primary combustion zone. The temperature at the outlet of the furnace rises slightly, but the effect is small. The volume fraction of $\mathrm{CO}, \mathrm{CO}_{2}$, and $\mathrm{NO}$ in the flue gas has the same distribution law as that of pure coal combustion. After the mixed combustion, the volume fraction of $\mathrm{CO}_{2}$ at the furnace outlet slightly increases. The higher the position of the biomass nozzle, the lower the NO emission.

\section{References}

1. XIAO Yang, LIU Haifeng, LI Na. Development and utilization of biomass energy [J]. Hubei Agricultural Mechanization, 2020(09) : 44-45.

2. Chen Rui, Zhang Zheming, Cao Li.c Current status and market prospects of biomass power generation industry [J].Market Weekly, 201, 34(01) : 39-41.

3. Stroh A., Alobaid F., Busch J. P., et al. 3-D numerical simulation for co-firing of torrefied biomass in a pulverized-fired $1 \mathrm{MW}$ the combustion chamber[J]. Energy, 2015, 85: 105-116.

4. Magdziarz A., Wilk M. Thermogravimetric study of biomass sewage sludge and coal combustion[J]. Energy Conversion and Management, 2013, 75: 425-430

5. LU Guangwu, CHEN Hai-ping. Combustion characteristics and kinetic analysis of biomass and coal blended [J].Power System Engineering, 2013, (04) : 7-9+11.

6. TIAN Hong, LIAO Zhengzhu. Co-combustion of biomass straw and bituminous coal: Characteristics and kinetics study [J].Thermal Power Generation, 2014,43 (08) : 52-59.

7. Zhang Jin. Experimental study and numerical simulation of co-combustion of coal and biomass in fluidized bed [D]. Southeast University, 2017.

8. Li Jiahu, Wang Xiaotao, Gao Shuo, et al. Numerical Simulation on Co-firing Characteristics of Coal and Biomass Gas in a $300 \mathrm{MW}$ Boiler[J].Journal of Chinese Society of Power Engineering, 2020,40(06):440-446.

9. Wang Kai. Numerical study on nitrogen oxides control of co-firing biomass with coal in a 670MW Boiler [D].Huazhong University of Science and Technology, 2019

10. Khorshidi Z., T. Ho M., E.Wiley Dianne. Techno-economic study of biomass co-firing with and without $\mathrm{CO} 2$ capture in an Australian black coal-fired power plant[J]. Energy Procedia, 2013, 37: 6035-6042.

11. Sung Y., Lee s., Kim C., et al. Synergistic effect of co-firing woody biomass with coal on NO $\mathrm{x}$ reduction and burnout during air-staged combustion[J]. Experimental Thermal and Fluid Science, 2016, 71: 114-125. 